\title{
Social Determinants of Health at Different Phases of Life
}

\author{
Susanna Toivanen • Bitte Modin
}

Published online: 12 January 2011

(C) International Society of Behavioral Medicine 2011

Social determinants of health, i.e., those conditions under which people are born, live, work, and grow old, shape population health in a systematic way [1].Unequal distribution of and access to resources such as power, education, income, goods, and services, influences social inequalities in health between countries and between groups of people within countries. The common features of social determinants of health are that they vary across time and space, that they accumulate throughout the life course, and that they act on multiple levels in a society ranging from upstream determinants in terms of social institutions and policies via intermediate levels of interpersonal social relationships and individual risk factors to downstream determinants of pathophysiologic bodily pathways (Fig. 1) [2].

This multilevel understanding of social determinants of health highlights the scope for reciprocal influences between the different levels, something which may give rise to complex causal chains over the life course. Within the framework of social determinants of health the aim of the Editorial for this issue of International Journal of Behavioral Medicine is to emphasize six studies of psychological and social conditions under different phases of life in relation to a number of health-related outcomes as illustrated in Fig. 2 [3-8].

Over the last few decades, it has become increasingly clear that the foundation of good health is laid down in early life $[9,10]$. In order to understand how contemporary health differences came about, hence, past circumstances need to be elucidated. Focusing on the life-course effects of

S. Toivanen $(\bowtie) \cdot$ B. Modin

Centre for Health Equity Studies|CHESS,

Stockholm University/Karolinska Institute,

10691, Stockholm, Sweden

e-mail: susanna.toivanen@chess.su.se social adversity, study 1 by Temcheff et al. and study 2 by Jonassaint et al. investigate the links between childhood circumstances and adult health correlates while also taking socioeconomic circumstances in young adulthood into consideration $[4,5]$.

In study 1 , the focus is on childhood behavior in terms of aggression, social withdrawal, and likeability and their relation to adult physical health measured as total medical acts, lifestyle illnesses, and injuries [5]. Interestingly, behavior characteristics were assessed by classroom peer nominations, and the results indicated that both aggression and likeability during childhood were directly linked to the studied health outcomes two to three decades later in life. Although the effects were small, childhood aggression and likeability were also found to be indirectly linked to the three studied health outcomes via attained education. The findings by Temcheff et al. add to the existing literature on long-term health correlates of classroom peer nominations $[11,12]$ by discerning both direct and indirect pathways from childhood behaviors to adult physical health, something which is key to both prevention and intervention.

Childhood behaviors partly reflect individual traits but may also be the result of past and present family circumstances. For example, the lasting impact of parents' socioeconomic status (SES) on their children's social trajectories and health is well established [9, 13, 14]. Behaviors such as aggression, social withdrawal, and likeability, hence, do not only reflect situational demands and constrains, but also mirror the individual's personality and social background [15]. A potential pathway through which SES could influence later life health could therefore be assumed to operate via the individual's personality.

In the present issue, Jonassaint and co-authors (study 2, Fig. 2) expand this strand of research by investigating the life-course SES in relation to personality patterns in 


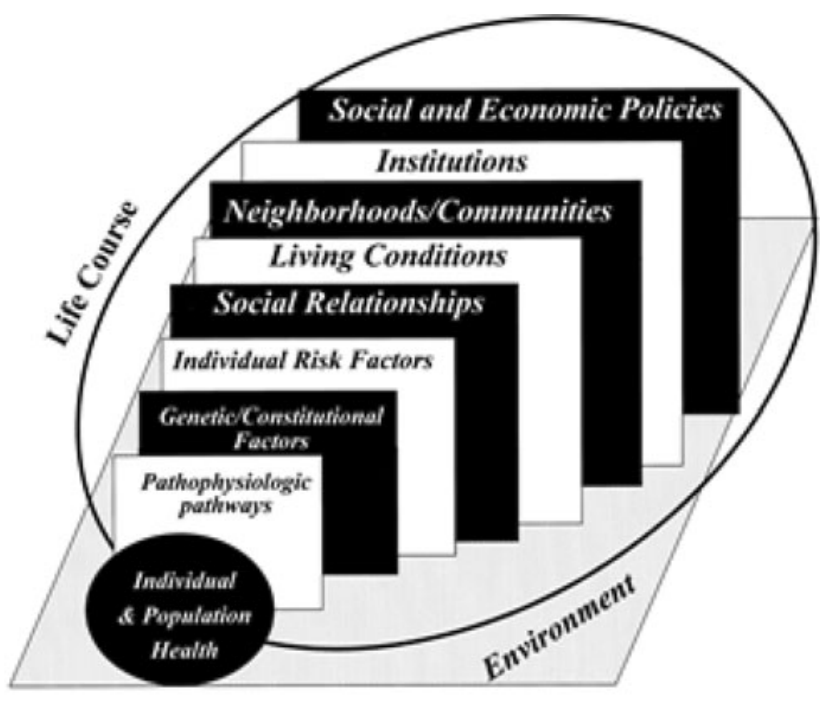

Kap Ian G A Ep Idem lol Fo v 2004,26:124-136

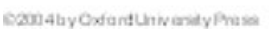

Fig. 1 Upstream and downstream determinants of population health

adulthood as assessed by the five-factor model. The results show that both retrospectively assessed parental SES and participant's current SES have significant main relationships with personality. The authors conclude that although childhood conditions are important, the combination of having experienced favorable SES conditions in both childhood and adulthood may be necessary for optimal coping and longevity in adult life. High life-course SES may indicate an accumulation of resistance to stress that is not evident to the same extent in socially mobile or persistently low life-course SES individuals. Although study 2 cannot provide any evidence that the association between SES and health is partly or fully accounted for by personality, the presented link between life-course SES and adult personality traits is at least consistent with such an assumption.

Study 3 by Kopp et al. digs deeper into the issue of gender differences in the association between SES and health by studying premature mortality among middle-aged Hungarian women and men of various social backgrounds [3]. It is widely established that although women generally experience poorer socioeconomic circumstances than men, they have greater life expectancy, but they also suffer more morbidity. Men's commonly found steeper SES gradients in health are sometimes suggested to manifest a "general pattern". However, relative SES differences in mortality among women and men have been found to be sensitive to the choice of SES measure [16]. Moreover, SES differences in mortality are generally larger in Central and Eastern European (CEE) countries than in Western European countries, mainly due to the communist past and rapid social transitions since the early 1990s [17]. A few previous studies of SES differences in mortality that are based on CEE countries report gender-specific results [18, 19], but no study has so far focused specifically on the gender patterns of SES differences in mortality. Therefore, the
Fig. 2 Study design and levels of analysis of included studies. $A W L$ agression, social withdrawal, and likeability; $E d u$ attained education; NEOAC neuroticism, extraversion, openness to experience, agreeableness, and conscientiousness; SES socioeconomic status, CVD $\& P S$ cardiovascular reactivity and post-stress recovery

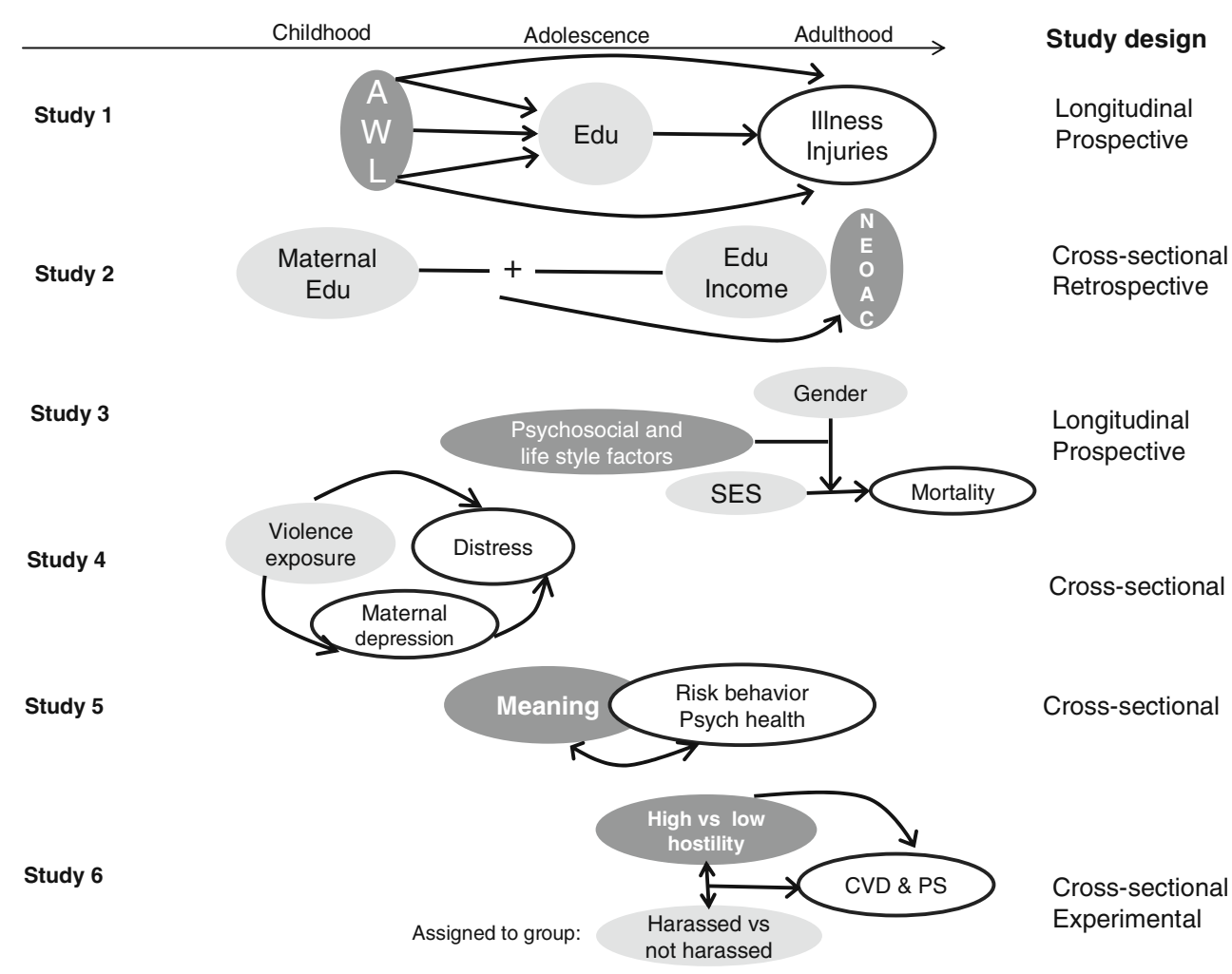


study by Kopp et al. in the present issue offers a major methodological improvement of the research field as it aims at quantifying the gender differences in the association between SES and premature mortality.

The authors carry on the analyses by testing six SES indicators, by assessing the interaction between gender and SES in relation to mortality using a synergy-index, and finally by studying whether psychosocial and lifestyle factors might account for the SES differences in mortality among women and men. The results show that each SES indicator was more deleteriously associated with mortality in men than in women, and that the strength of the interaction effect by gender varied across different SES measures. Also the explanatory factors differed by gender as adjustment for severe depression considerably reduced the SES gradient in premature mortality for men, but not for women. Among women, the SES gradient in mortality was somewhat explained by work stress and social support. The authors conclude that there are huge differences between male and female gender roles in Hungary, something which might partly explain the fact that men seem to be more vulnerable to chronic stress of material disadvantage than women. In addition, the connection between low SES and depressive symptoms is stronger among men than women in Hungary.

Still, depression is about half as common in men as it is in women [20] and at younger ages, internalizing symptoms, known as important precursors of adult depression, are also generally found to be more common among girls than among boys [21]. While life-course approaches to childhood social conditions are bound to draw upon information from the past, the study of present-day children's and adolescent's circumstances in relation to their psychological health is important to describe as well even if it often means that one has to analyze cross-sectional data. The immediate implications of young people's conditions for their psychological well-being are investigated in studies 4 and 5. Study 4 by Suglia et al., in which children's exposure to violence are analyzed in relation to distress symptoms, points to the importance of asking children and adolescents themselves about their circumstances, especially those concerning self-perceived health since it is difficult for parents to provide information about these matters [7]. Suglia et al. use both parent and child report of violence exposure, and finds that the latter predicts a broader range of distress symptoms compared to the former. Analyses based on maternal reporting, on the other hand, revealed a significant mediation effect of maternal depression on the studied relationship.

Adolescence represents a vulnerable period that may bring about both short- and long-term health consequences [22]. In addition, personal attributes, poverty, and lack of psychological and social resources may increase adoles- cents' vulnerability to health risk behaviors, such as smoking, binge drinking, and substance abuse, and associated poor health outcomes. Yet, despite exposure to severe hardship, some individuals seem to be resilient to stress and thus protected against its adverse health effects. In study 5 by Brassai et al., the focus is on coherent meaning as a protective factor for health risk behaviors and psychological health in a largely unstudied population of adolescents in Romania [8]. In line with previous research, meaning in life appeared to serve as a protective factor against several health risk behaviors and poor psychological health among the studied adolescents. However, the study also provides new findings as it suggests gender differences in the associations between protective factors and health risk behaviors. While the levels of meaning of life did not vary as a function of gender, the patterns of associations between meaning in life and health-related variables differed among these young women and men. Therefore, although crosssectional, the results add to our present knowledge about the interplay of protective factors and health risk behaviors among adolescents.

The sixth study by Neumann et al. further elaborates the question of how personality is linked to health by investigating how people's level of hostility interacts with situational circumstances in terms of exposure to harassment to cause cardiovascular and psychological reactivity and recovery. The results showed that having been exposed to a harassment situation was negatively associated with cardiovascular responses and positive affect regardless of whether the person was classified as having high or low hostility levels. Thus, high hostile persons displayed blunted, rather than exaggerated cardiovascular reactivity compared to low hostile persons. The hypothesized interaction between hostility and harassment on cardiovascular responses was not confirmed, but it was instead found that hostility and exposure to harassment interacted to cause an elevated level of blame attribution, something which is contrary to results reported in prior studies.

To summarize, the six studies of the present issue of International Journal of Behavioral Medicineare serve as good examples of the wide variety of topics that are commonly investigated within the interdisciplinary research field of social determinants of health and health inequalities. Our aim was to put the studies in a wider social context as presented by Fig. 1. The model stresses the importance of focusing on a broad array of social factors when studying the development and reproduction of health problems. While the present studies contribute to increased understanding of the meaning of social factors for the etiology of many important health problems, we need to keep in mind that focusing only on one level of analysis may lead to an oversimplification of the studied associations. 


\section{References}

1. World Health Organization, Commission on Social Determinants of Health. Closing the gap in a generation: health equity through action on the social determinants of health. Geneva: World Health Organization; 2008.

2. Kaplan GA. What's wrong with social epidemiology, and how can we make it better? Epidemiol Rev. 2004;26:124-35.

3. Kopp M, Skrabski Á, László K, Janszky I. Gender patterns of socioeconomic differences in premature mortality: Follow-up of the Hungarian Epidemiological Panel. Int J Behav Med. 2010. doi:10.1007/s12529-010-9126-5.

4. Jonassaint CR, Siegler IC, Barefoot JC, Edwards CL, Williams RB. Low life course socioeconomic status (SES) is associated with negative NEO PI-R personality patterns. Int J Behav Med. 2010. doi:10.1007/s12529-009-9069-x.

5. Temcheff CE, Serbin LA, Martin-Storey A, Stack DM, Ledingham J, Schwartzman AE. Predicting adult physical health outcomes from childhood aggression, social withdrawal and likeability: a 30-year prospective longitudinal study. Int J Behav Med. 2010. doi:10.1007/ s12529-010-9082-0.

6. Neumann SA, Maier KJ, Brown JP, Giggey PP, Cooper DC, Synowski SJ, et al. Cardiovascular and psychological reactivity and recovery from harassment in a biracial sample of high and low hostile men and women. Int J Behav Med. 2010. doi:10.1007/ s12529-010-9110-0.

7. Suglia SF, Ryan L, Bellinger DC, Bosquet Enlow M, Wright RJ. Children's exposure to violence and distress symptoms: influence of caretakers' psychological functioning. Int J Behav Med. 2010. doi:10.1007/s12529-010-9090-0.

8. Brassai L, Piko BF, Steger MF. Meaning in life: is it a protective factor for adolescents' psychological health? Int J Behav Med. 2010. doi:10.1007/s12529-010-9089-6.

9. Galobardes B, Lynch JW, Davey Smith G. Is the association between childhood socioeconomic circumstances and causespecific mortality established? Update of a systematic review. J Epidemiol Community Health. 2008;62(5):387-90.
10. Kuh D, Ben-Shlomo Y. A life course approach to chronic disease epidemiology: tracing the origins of ill-health from early to adult life. Oxford: Oxford University Press; 1997. p. 285-93. Vol. 32, Issue 2.

11. Zettergren $\mathrm{P}$, Bergman LR, Wångby $\mathrm{M}$. Girls' stable peer status and their adulthood adjustment: a longitudinal study from age 10 to age 43. Int J Behav Dev. 2006;30:315-25.

12. Östberg V, Modin B. Status relations in school and their relevance for health in a life course perspective: findings from the Aberdeen children of the 1950s cohort study. Soc Sci Med. 2008;66(4):83548.

13. Erikson R, Goldthorpe JH. The constant flux: a study of class mobility in industrial societies. Oxford: Clarendon; 1992.

14. Erola J, Moisio P. Social mobility over three generations in Finland, 1950-2000. Eur Sociol Rev. 2007;23(2):169-83.

15. McCrae RR, Costa PTJ. Personality in adulthood: a five-factor theory perspective. New York: The Guildford; 2003.

16. Mustard CA, Etches J. Gender differences in socioeconomic inequality in mortality. J Epidemiol Community Health. 2003;57 (12):974-80.

17. Kunst AE. Socioeconomic inequalities in health in Central and Eastern Europe: synthesis of results of eight new studies. Int $\mathrm{J}$ Public Health. 2009;54(4):197-200.

18. Leinsalu M, Stirbu I, Vågerö D, Kalediene R, Kovács K, Wojtyniak B, et al. Educational inequalities in mortality in four Eastern European countries: divergence in trends during the postcommunist transition from 1990 to 2000. Int J Epidemiol. 2009;38(2):512-25.

19. Mackenbach JP et al. Socioeconomic inequalities in mortality among women and among men: an international study. Am J Public Health. 1999;89(12):1800-6.

20. Noble RE. Depression in women. Metabolism. 2005;54(5 Suppl 1):49-52.

21. Leadbeater BJ, Kuperminc GP, Blatt SJ, Hertzog C. A multivariate model of gender differences in adolescents' internalizing and externalizing problems. Dev Psychol. 1999;35(5):1268-82.

22. Rew L. Adolescent health: a multidisciplinary approach to theory, research, and intervention. Thousand Oaks: Sage Publications; 2005. 